\title{
Regime de tempo no afrofuturismo a partir dos quadrinhos do Pantera Negra
}

\author{
Time Regime in the Afrofuturism from Black \\ Panther Comics
}

\author{
Micaella Schmitz Pinheiro ${ }^{1}$
}

\author{
DOI: $10.19177 /$ memorare.v8e12021141-159
}

\begin{abstract}
Resumo: 0 presente artigo buscou tratar da questão temporal no afrofuturismo, por meio dos quadrinhos do Pantera Negra, escrito por Stan Lee e desenhado por Jack Kirby, inicialmente em 1966, publicado pela Marvel Comics. 0 afrofuturismo é um movimento que "desliza" entre passado, presente e futuro. Sendo assim, pensando nesse regime de tempo, foi utilizado as ideias de Cronos e Aion, de Gilles Deleuze (2015). Sobre afrofuturismo, foram utilizados como pressupostos teóricos autores como Kênia Freitas (2020), Alondra Nelson (2002), Kodwo Eshun (2003) e Mark Dery (1993, 2018). Na primeira parte, o artigo introduz o conceito de afrofuturismo e apresenta o personagem Pantera Negra. 0 segundo momento se ocupa em realizar uma breve introdução da História americana nos anos de 1960 a partir dos quadrinhos. Em seguida, são apresentados os estudos sobre afrofuturismo e a questão do regime de tempo aionico e cronológico. Por fim, são feitas as considerações finais. Revelou-se, então, que o afrofuturismo não permanecer parado ou em um único regime de tempo, seja ele aion ou crônos.

Palavras-chave: Afrofuturismo. Pantera Negra. Regime de tempo.
\end{abstract}

\begin{abstract}
This article sought to address the temporal issue in Afrofuturism, by means of the Black Panther comics, written by Stan Lee and accompanied by Jack Kirby, bulletin in 1966, published by Marvel Comics. Afrofuturism is a movement that "slips" between past, present and future. Therefore, thinking about this time regime, the ideas of Cronos and Aion, by Gilles Deleuze (2015), were used. Regarding Afrofuturism, authors such as Kênia Freitas (2020), Alondra Nelson (2002), Kodwo Eshun (2003) and Mark Dery $(1993,2018)$ were used as theoretical assumptions. In the first part, the article introduces the concept of Afrofuturism and introduces the character Pantera Negra. The second moment is concerned with making a brief introduction to American history in the 1960s from the comics. Next, studies on Afrofuturism and the question of the aionic and chronological time regime are required. Finally, the final feats are made. It was revealed, then, that Afrofuturism will not remain stopped or in a single regime of time, be it aion or chronos.
\end{abstract}

Keywords: Afrofuturism. Black Panther. Time regime.

\footnotetext{
${ }^{1}$ Graduação em História. Mestre em Ciências da Linguagem pela Universidade do Sul de Santa Catarina. mica.schmitz26@gmail.com
} 


\section{Introdução}

O presente artigo busca tratar da questão temporal no afrofuturismo, por meio dos quadrinhos do Pantera Negra, escrito por Stan Lee e desenhado por Jack Kirby, inicialmente em 1966, publicado pela Marvel Comics. A história se passa em um reino localizado na África, chamado de Wakanda, o local foi afetado por um metal denominado de vibranium, que impulsionou o desenvolvimento de inúmeras tecnologias ao longo dos séculos. Por ter se tornado tão desenvolvida no âmbito econômico, social e tecnológico, os reis de Wakanda decidem esconder o local, para que não ocorram invasões. As principais habilidades do personagem estão relacionadas com a ancestralidade herdada de outros Panteras Negras, como uma super força e inteligência, além de habilidades para lutar. A sua primeira aparição foi em uma HQ em conjunto com o Quarteto Fantástico. Posteriormente, o personagem veio a ganhar uma revista solo.

Busca-se, portanto, analisar o regime de tempo do afrofuturismo sob uma perspectiva contra identitária, isto é, figuras do limiar entre identidade e não-identidade, potência, linhas de fuga de um determinado essencialismo da negritude. 0 artigo foi estruturado em oito seções, sendo a primeira a presente introdução. A segunda seção apresenta o personagem Pantera Negra. A seção seguinte apresenta uma breve introdução sobre a história de Jack Kirby nos quadrinhos. A quarta seção mostra a aparição do Pantera Negra no Cinema. A próxima apresenta uma breve história dos Estados Unidos e suas relações com os quadrinhos. A seção seguinte aborda sobre alguns conceitos de afrofuturismo. Na sétima seção são apresentadas as discussões acerca do regime de tempo no afrofuturismo. E por fim, são apresentados os resultados finais.

\section{Quem é o Pantera Negra?}

T’Challa é o nome dado ao personagem Pantera Negra. Sua primeira aparição em quadrinhos foi na edição 52 do Quarteto Fantástico (Figura 1). Por ser uma revista que possuía uma boa aceitação do público, tendo um número expressivo nas vendas, Jack Kirby e Stan Lee a utilizavam para apresentar novos personagens. Alguns exemplos são o Surfista Prateado, Thor, Hulk, Dr. Destino e o próprio Pantera Negra. A partir desse momento, o público passou a conhecer Wakanda e o Pantera Negra. 0 enredo se passa com um convite de T'challa ao Quarteto Fantástico para ir visitar Wakanda. Chegando lá, eles percebem que era uma armadilha, e o Pantera Negra inicia uma luta com os visitantes. Até esse momento não fica claro se o Pantera seria um vilão ou um "mocinho" na história. Por fim, Pantera Negra vence a disputa, e então, explica ao Quarteto que a ideia era testar suas habilidades, e saber se ele estaria preparado para defender Wakanda caso houvesse alguma invasão. Assim, eles acabam se tornando amigos, e o Quarteto inclusive ajuda a defender o local posteriormente. Desde o primeiro momento em que o grupo de heróis chega em Wakanda, eles apresentam espanto ao ver o desenvolvimento tecnológico do local. Assim, são perceptíveis os primeiros traços do afrofuturismo no quadrinho. 
Figura 1: Primeira aparição do Pantera Negra em HQ.

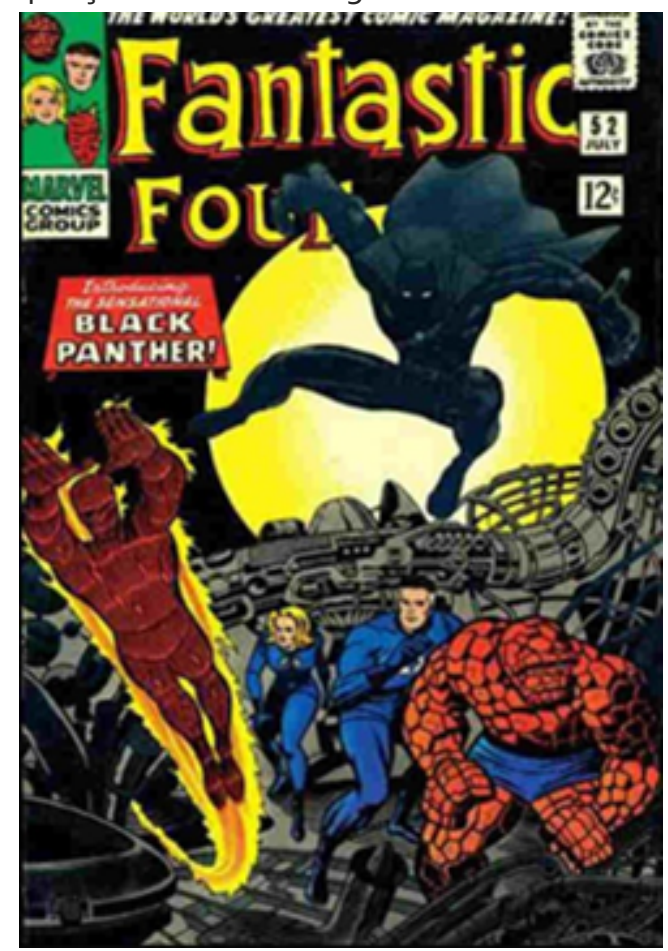

Disponível em: https://www.planocritico.com/critica-quarteto-fantastico-52-53-e56-primeira-aparicao-pantera-negra-ulysses-klaw-e-garra-sonica.

Após alguns conflitos, o rei T'challa conta a história do surgimento do Pantera Negra. O personagem surge com a queda de um meteoro em uma determinada região da África, que posteriormente seria conhecida como Wakanda. O que havia dentro do meteoro era um metal conhecido como vibranium. Dentro da história, a característica principal desse metal é a alta absorção de energia.

No período da queda do meteoro, existiam várias tribos habitando a região, e os moradores do local passaram a acreditar que o ocorrido havia sido um presente dos deuses. Com isso, tomaram como missão a proteção do metal. Entretanto a radiação do vibranium acabou transformando geneticamente algumas pessoas. Houve um ataque de espíritos ruins sobre o povo, e com o intuito de defender o local e as pessoas que ali viviam, surge o primeiro Pantera Negra.

0 vibranium, além de produzir os superpoderes dos Panteras Negras, também contribuiu para o desenvolvimento tecnológico de Wakanda. A população e o rei preferem esconder a cidade, pois dessa forma, ficariam protegidos de invasões. Entretanto, o Pantera Negro T'Chaka, pai de T'Challa, vendia pequenas porções do metal para cientistas de outros países. Com o dinheiro, enviava os melhores alunos de Wakanda para estudar em diferentes universidades. Porém, em determinado momento, o metal passa a despertar o interesse de alguns cientistas, e ocorre a invasão pelo físico holandês Ulysses Klaw, que procura explorar o metal. Ele não conseguiu arrecadar o material, mas acabou matando T'Chaka. Posteriormente, o físico se tornou o arquiinimigo do Pantera Negra nos quadrinhos, e passou a ser chamado de Garra Sônica. 0 nome Garra Sônica é referente ao braço de metal que Klaw precisou implantar após a primeira disputa por vibranium, pois durante a luta com T'Challa, ele acabou perdendo um dos braços. 
Não existe apenas um Pantera Negra, o "cargo" vai sendo passado através das gerações. E com a morte de T"Chaka, o sucessor seria o seu filho, T'Challa. Quando ocorreu a eleição de um novo Pantera Negro, foi realizado um ritual, onde T'Challa comeu uma erva afetada por vibranium. Isso faz com que ocorra a transferência de poderes sobrehumanos, como força e sabedoria extrema. Além disso, as experiências dos Panteras anteriores foram transferidas para o novo escolhido. Para manter a paz na região, T'Challa contou com a ajuda de diferentes mulheres de tribos africanas que foram treinadas para defendê-lo.

Em sua primeira aparição nos quadrinhos do Quarteto Fantástico, T'Challa havia enviado de presente ao Quarteto Fantástico uma nave com tecnologia avançada e convidou o grupo para visitar Wakanda. Nesse primeiro momento, ficou claro que até então eles não conheciam nada sobre Wakanda ou sobre o próprio Pantera Negra. Desde o primeiro encontro o grupo se surpreendeu com a tecnologia que T'Challa possuía, pois até então eles nunca tinham visto nada igual. Ao chegar em Wakanda, o Pantera Negra havia montado uma armadilha para o grupo. Entretanto, eles conseguem escapar. T'Challa então explicou que a armadilha foi feita para ele se auto testar, pois precisava saber se estaria preparado para enfrentar o seu inimigo Garra Sônica. Por fim, Pantera Negra e o Quarteto Fantástico tornam-se amigos, e acabam lutando lado a lado.

Após a sua apresentação nas edições de número 53 e 54 do Quarteto Fantástico, o personagem retornou na edição anual de número 5 em 1967 (Figura 2). Momento em que ocorreu uma ajuda simultânea entre o Pantera Negra e o Quarteto Fantástico.

Figura 2: Edição Anual do Quarteto Fantástico em 1963.

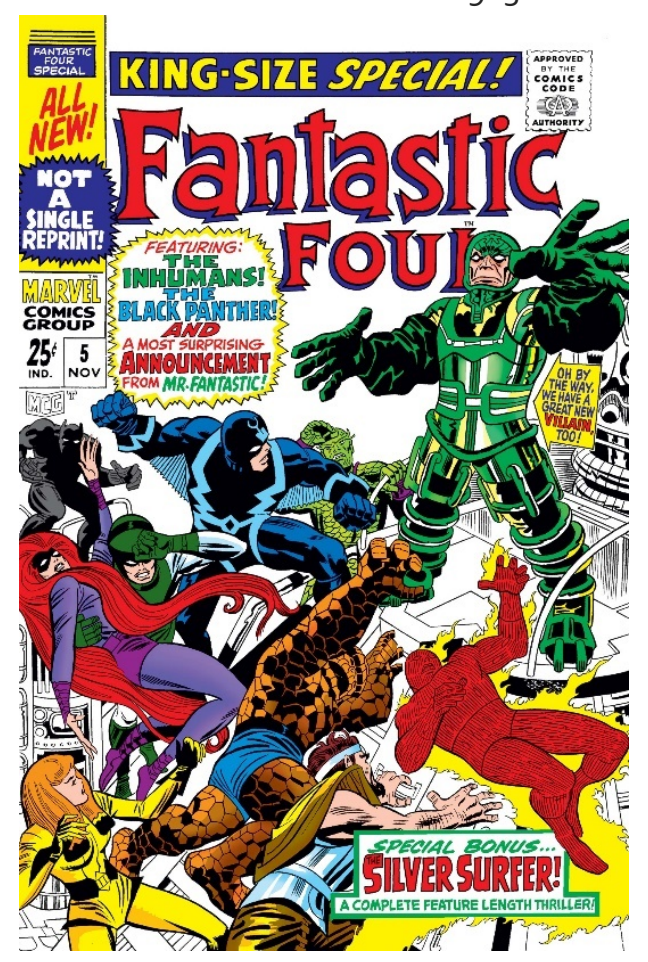

Disponível em:

https://www.marvel.com/comics/issue/8709/fantastic_four_annual_1963_5 
As próximas vezes que o Pantera Negra iria ser visto nos quadrinhos foram nas edições de número 97 e 99 do Capitão América em 1968. Desta vez, como pode ser observado nas capas, o personagem ganhou mais destaque, sendo inclusive descrito como inimigo do Capitão América, um dos personagens mais populares durante o período da Segunda Guerra Mundial, justamente por representar o patriotismo americano. (Figuras 3 e 4).

Figura 3: HQ do Capitão América número 97.

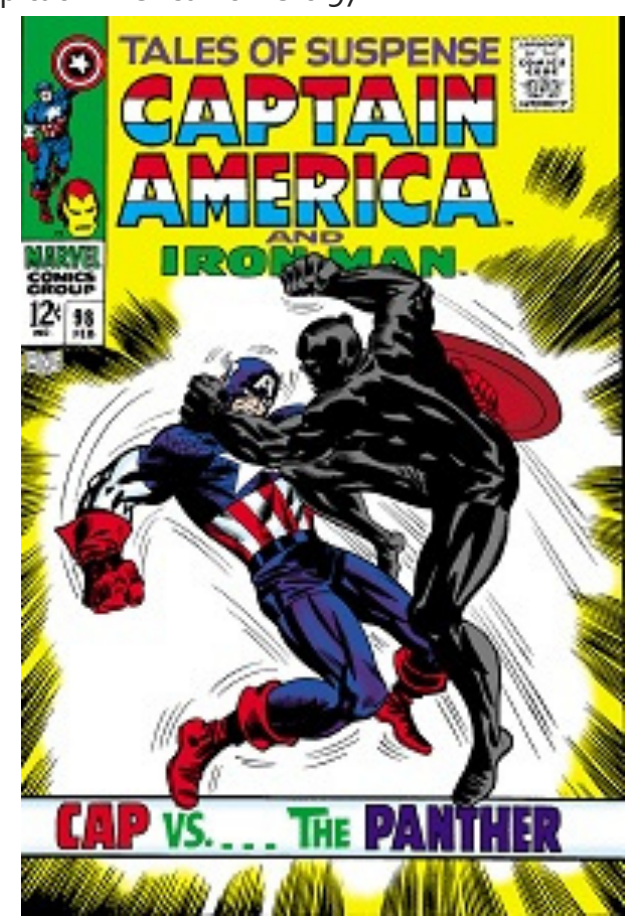

Disponível em: https://thevirtuesofcaptainamerica.com/2018/10/26/tales-ofsuspense-97-99-and-captain-america-100-january-april-1968

Figura 4: HQ do Capitão América número 99.

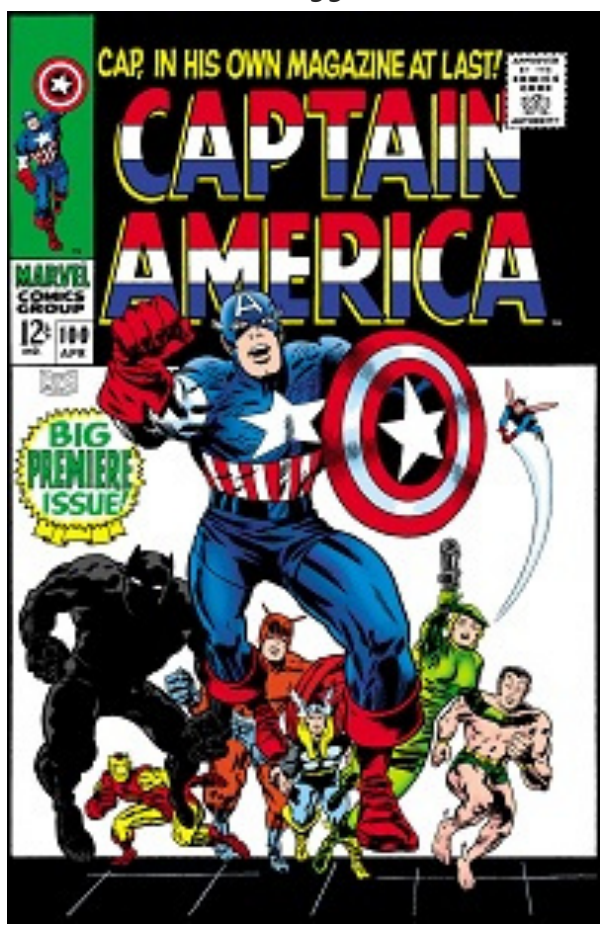

Disponível em: https://thevirtuesofcaptainamerica.com/2018/10/26/tales-ofsuspense-97-99-and-captain-america-100-january-april-1968

Memorare, Tubarão, v. 8, n. 1, jan./jun. 2021. ISSN: 2358-0593 
O enredo Tales of Suspense, edições 97-99 (1968), se passou com o Pantera Negra saindo de Wakanda para ir à Nova York, onde ele se juntou à equipe de super-heróis denominada de Vingadores, composta por Capitão América, Thor, Homem de Ferro, Homem-Formiga, Vespa e Hulk. (Figura 5). Nem todos os personagens foram introduzidos ao mesmo tempo. 0 Pantera Negra teve sua primeira aparição na edição de número 52, em maio de 1968 e continuou nas revistas dos anos seguintes.

Figura 5: Primeira aparição do Pantera Negra com os Vingadores.

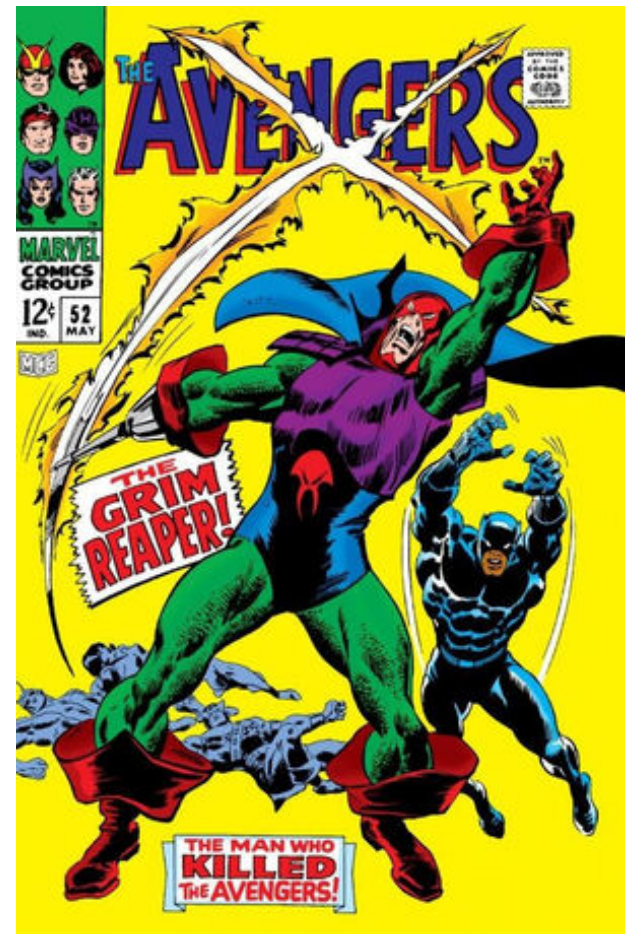

Disponível em: https://marvel.fandom.com/wiki/Avengers_Vol_1_52

Durante seu tempo com os Vingadores, Pantera Negra fez aparições em outras HQs, como Demolidor e em Astonishing Tales. Foi a partir dos anos de 1970 que o Pantera Negra passou a ter a sua revista própria, fazendo parte do projeto Jungle Action. A revista Jungle Action possuía versões anteriores, com a primeira publicação em 1954, sendo cancelada 1955. A ideia principal era abordar sobre "tramas da selva", apresentando personagens como Lo-Zar, Senhor da Selva, Menino das Selvas e Mulher Leopardo/Gwen.

\section{A ascensão de Jack Kirby nos quadrinhos}

Com todas as mudanças sociais que ocorridas na sociedade americana dos anos de 1960, como a Guerra Fria, a Guerra do Vietnã, a luta dos direitos civis e o movimento da contracultura, os quadrinhos de super-heróis tiveram uma queda nas vendas. Com isso, as editoras passaram por reformulações, especialmente relacionadas com as características dos super-heróis. A partir deste momento, os personagens passaram a apresentar uma postura mais engajada com a realidade do período, abordando sobre questões sociais e políticas e Jack Kirby teve um papel fundamental nessa mudança. 
Alguns anos antes desses fatos ocorrerem, Kirby já estava trabalhando com quadrinhos, e por volta de 1950, após um período trabalhando para a Fox, Kirby conseguiu uma vaga de diretor de arte na Timely Comics (que posteriormente se torna Atlas Comics e, tempos depois, viria a se tornar a Marvel Comics). Na atual editora, Kirby continuava o seu trabalho em conjunto com Joe Simon. Durante o seu tempo na Timely, o autor criou um dos seus maiores sucessos: Capitão América. 0 personagem passa a representar parte da realidade do mundo, lutando com personagens reais, como Adolf Hitler. Nessa HQ, Kirby misturou todo o seu repertório, desde política, ficção científica a mitologia.

Foi nesse período que Kirby conheceu Stan Lee. Até então, eles não tinham contato direto, porém, nos anos seguintes, se tornaram parceiros no desenvolvimento das HQs. A primeira participação dos dois juntos foi em uma história do Capitão América, onde Lee escreveu a história e Kirby desenhou. Após descobrir que Martin Goodman, dono da então Marvel Comics, não estava repassando o valor correto sobre as histórias do Capitão América, Jack Kirby e Joe Simon foram procurar a principal concorrente da editora na época, a DC. Comics. (SCIOLI, 2020).

Nos anos 60, após ter passado por algumas editoras, Kirby volta para a Marvel e em 1961, ele é novamente apresentado para Stan Lee, que havia se tornado roteirista e editor. Os dois tiveram uma longa parceria, que gerou a criação de diversos super-heróis, como Thor, Hulk, Surfista Prateado, Dr. Destino, Pantera Negra e até mesmo retomaram a ideia de equipe de heróis juntos, com os X-Men e Os Vingadores. Os dois fizeram muito sucesso, e a venda das HQs no período voltou a crescer. Entretanto, após alguns desentendimentos com a Marvel, Kirby retorna para a DC Comics. Os quadrinhos desse período passaram a apresentar uma linguagem mais coloquial, com o uso de gírias, e os personagens com traços mais humanos, apresentando problemas mais reais e cotidianos. Sendo considerado um dos maiores desenhistas, Kirby criou personagens e conceitos, mudando o formato das histórias em quadrinhos, com o uso de página dupla e o senso de ação dos personagens, fez com que as editoras tivessem muito sucesso. (HATFIELD, 2011)

Em 1972 houve a republicação das Jungle Action. Suas primeiras edições continuaram com as mesmas ideias do modelo anterior, contanto histórias que se passavam na selva. No mesmo período houveram algumas reimpressões de sagas do passado. Foi na edição de número 5 que o Pantera Negra faz a sua primeira aparição (Figura 6). A narrativa baseava-se em uma luta do super-heróis Pantera Negra, Visão, Gavião Arqueiro e o convidado Cavaleiro Negro III contra o Homem Gorila. Nessa história, o vilão era um líder de umas das tribos presentes em Wakanda. Ele atacou os estrangeiros, mesmo contra as ordens de $\mathrm{T}^{\prime}$ Challa, e depois os envenenou. Esse foi o primeiro roteiro que trouxe ao centro o personagem do Pantera Negra. As edições seguintes de Jungle Action passaram a apresentar histórias inéditas sobre o Pantera Negra e Wakanda e o personagem passou a ganhar todas as capas das próximas edições. 
Figura 6: Primeira edição de Jungle Action com aparição do Pantera Negra.

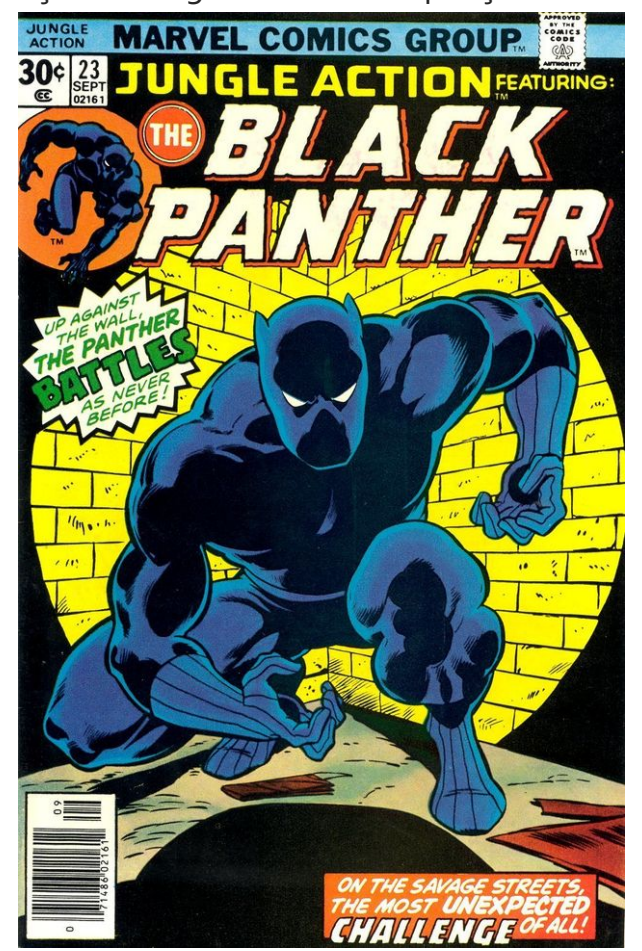

Disponível em: https://www.huffpostbrasil.com/2018/02/15/pantera-negraentenda-a-origem-e-a-importancia-do-10-super-heroi-negro-

mainstream_a_23362850

Após a publicação de 13 volumes, as vendas da Jungle Action foram baixas, em 1976 a revista foi cancelada. Entretanto, a Marvel relançou o personagem em uma série intitulada Pantera Negra, que ganhou 12 edições criadas por Jack Kirby. Entretanto, Kirby não estava satisfeito em continuar produzindo histórias para o mesmo personagem, e foi substituído por Ed Hannigan, roteirista e Jerry Bingham, desenhista. No total, foram 15 edições entre 1977 e 1979, ano em que as histórias foram canceladas.

Outros autores tentaram dar continuidade a história do Pantera Negra. Em 1988 foi publicado uma minissérie de quatro edições, Black Panther vol. 2 escrita por Peter B. Gillis e desenhada por Denys Cowan. No mesmo ano foi lançado The Black Panther vol. 3, escrito por Christopher Priest e desenhado por Mark Texeira. Essa versão contou com personagens já existentes em Jungle Action, além de introduzir outros personagens, como o agente americano Everett Ross, o irmão adotivo do Pantera negra, Hunter e a Rainha Justiça Divina. Esse volume ganhou o selo Marvel Knights, que determinava uma certa classificação para a história, sendo recomendada para adolescentes mais velhos e adultos. A série escrita por Priest foi publicada até 2003.

Em 2005, a Marvel publicou Black Panther vol. 4, escrita majoritariamente por Reginald Hudlin e desenhada por John Romita, Jr. Um ano depois, Black Panther vol. 5 foi lançada, mais uma vez escrita por Hudlin e Jonathan Maberry, o responsável pela ilustração dessa edição foi Will Conrad. Foi no volume 5 que Shuri, a irmã de T'Challa foi apresentada como sua sucessora. Em 2010 ocorre a aparição do Pantera Negra, em conjunto com o Quarteto Fantástico e os X-men, na minissérie Doomwar. Posteriormente, em 2011, o personagem apareceu em com 
conjunto com o Demolidor, escrita por David Liss e ilustrada por Francesco Francavilla. Anos depois, em 2016, o personagem ganhou novamente uma edição só sua, escrita por Ta-Nehisi Coates, que vem sendo publicada até os dias atuais. Em 2017, a escritora Nnedi Okorafor também passou a publicar histórias do Pantera Negra. Atualmente a autora se dedica a escrever uma série solo para Shuri, irmã de T'Challa.

\section{A adaptação para o cinema}

O universo Marvel vem sendo adaptado para o cinema desde 2008. Após a gravação de alguns personagens solo como Homem de Ferro, Hulk, Thor e Capitão América, no ano de 2012 foi lançado a primeira adaptação denominado Vingadores que une os principais personagens. Assim como na HQ, o personagem Pantera Negra apareceu em conjunto com os Vingadores. Mas é oficialmente em 2018 que o personagem ganhou uma adaptação cinematográfica solo, baseado nas HQs da Marvel Comics, produzida pela Marvel Studios e distribuída pela Walt Disney Studios Motion Pictures. 0 filme gerou 1,344 bilhão de dólares em bilheteria. E em 2019, recebeu seis indicações ao Oscar, saindo vencedor de três.

0 termo afrofuturista já havia sendo discutido desde os anos de 1990, especialmente nos Estados Unidos. Porém, após o filme, ocorreu uma retomada do conceito, justamente por mostrar diversas características afrofuturistas, como nas roupas usadas pelos personagens, no idioma (em Wakanda a língua principal é inglês, mas existe um dialeto local), na arquitetura, nas armas e em toda a tecnologia apresentada. (Figura 7). Além disso, há uma relação direta entre os povos de Wakanda e as tribos africanas. No filme, a mãe Romanda utilizou um chapéu que é característicos das mulheres casadas da tribo Zulu, localizada na África do Sul. Os pratos nos lábios, que o líder da tribo do rio aparece usando no filme, são característicos de tribos da Etiópia, como a Surma e Mursi. A tribo dos mineradores que apareceu usando uma coloração vermelha na pele representa os Himbas, localizados na Namíbia. As roupas das guerreiras Doras Milaje são inspiradas na tribo Massai, provenientes da Tanzânia e Quênia. As cicatrizes que o vilão Erik possuía no corpo são características de um ritual feito com homens da tribo Kaningara, de Papua Nova Guiné. (AUGUSTO, 2018).

Figura 7: Roupas, armas e tecnologia de Wakanda.

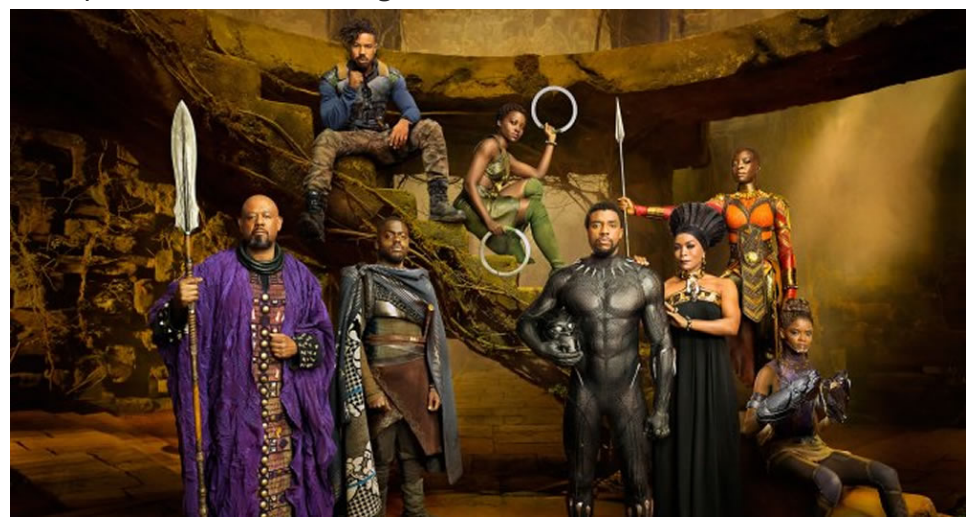

Disponível em: http://depositonerd.com.br/revelado-as-descricoes-dospersonagens-no-filme-do-pantera-negra

Memorare, Tubarão, v. 8, n. 1, jan./jun. 2021. ISSN: 2358-0593 
Pantera Negra tem sua importância histórica, social e cultural, pois com esse quadrinho, ocorreu uma oportunidade de representação para as pessoas negras. 0 filme, apesar de ser construído após a criação do conceito de afrofuturismo, é baseado nas HQs. E desperta para um novo olhar sobre a cultura africana. Muitos filmes estereotipam os negros como bandidos ou escravos, havendo poucas produções que mostrem o protagonismo negro de forma positiva. Nesse sentido, as HQs têm um papel importante, pois após a criação do Pantera Negra, outros superheróis negros surgiram, como Luke Cage, Tempestade, Lanterna Verde, Raio Negro, Super-Choque, Misty Knight, Lucas Bishop e Irmão Vodu. Existiu ainda um personagem pioneiro, anterior a todos os outros, que ficou conhecido como Lion Man, criado por Orrin Cromwell Evans em 1947, lançado na HQ All-Negro Comics.

\section{Uma breve introdução sobre o cenário norte-americano nos anos de 1960 a partir dos quadrinhos}

O século XX foi um período marcado por diversas guerras e revoluções. Não há como separar as histórias em quadrinhos dos movimentos sociais que ocorreram no contexto norte americano. É a partir de 1960 que os personagens negros passaram a ganhar um certo destaque nos quadrinhos americanos de super-heróis. Isso não significa que anteriormente não existissem personagens negros, pelo contrário, eles existiam, ainda que em menor escala, mas eram sempre caracterizados como uma figura estereotipada, sendo representados como vilões ou personagens cômicos.

O surgimento do herói e super-herói correspondeu a um determinado contexto histórico e social, marcados pela crise de 1929, a emergência da Segunda Guerra Mundial e o papel dos Estados Unidos da América. 0 mundo dos super-heróis passou a ter uma função propagandista, determinando valores hegemônicos na sociedade. Nessa conjuntura, explicita-se o caráter político das Histórias em Quadrinhos. (VIANA, 2005).

Acredita-se que o primeiro herói negro foi Lothar, de Mandrake, o Mágico criado em 1934. O personagem foi desenhado por Lee Falk. Na história, esse personagem era responsável por caçar criminosos. Lothar era apresentado utilizando uma pele de leopardo como vestimenta e uma espécie de chapéu vermelho. Foi apenas por cerca de 1940 em diante que os personagens negros começaram a deixar de ser coadjuvantes e se tornaram protagonistas das histórias.

Como pode ser visto, diante da luta pelos direitos civis, a comunidade afro-americana vinha sendo discriminada. Isso fez com que eles se organizassem e criassem movimentos próprios, como o Partido dos Panteras Negras e o movimento Black Power. Em 1966, o termo Black Power foi anunciado por Stokely Carmichael, um ativista do movimento negro, que vinha desde 1960 lutando pelos direitos civis da comunidade afro-americana. Para Coelho (2004, p. 82) "a partir deste momento o Black Power deixava de ser uma simples retórica e passava a ser, para muitos, a saída do movimento negro".

O movimento do Black Power ocorreu no mesmo período que a ascensão do Partido dos Panteras Negras, entre 1960 e 1970. Esse movimento marcou o modo de vida da comunidade negra 
estadunidense. Além do uso de cabelos Black Power, surgiram lemas como "I'm black and I'm proud" e "Black is beautiful". Neste momento, houve a inclusão de pessoas negras em esportes e manifestações culturais. (ALVES, 2011).

Outro movimento foi a criação do Partido dos Panteras Negras, por Huey P. Newton e Bobby Seale, em 15 de outubro de 1966, na Califórnia. Para Coelho (2004, p. 82) "mais do que representante da população negra dos guetos das grandes cidades, o partido se tornou durante alguns anos a maior referência de ação política no que diz respeito às suas táticas, aos ideários e aos modelos de conduta". De acordo com Johnson

Ao pensar sobre o Partidos dos Panteras Negras, pode-se perpassar por duas fases. No primeiro momento, de 1966 a 1971, o partido é visto como um acontecimento fundamentalmente californiano, contando com poucos jovens negros, que buscavam ajudar a própria comunidade, no sentido de protege-la, especialmente da violência policial. Eles "patrulhavam as ruas, armados, e, quando confrontados pela polícia, expressavam de forma contundente seu direito constitucional de portar armas, numa audácia que impressionou a comunidade negra da região da baía de São Francisco". (JOHNSON, 2002, p. 97)

Um ano após a sua fundação, o partido passou a ser reconhecido nacionalmente, após um protesto realizado na Assembleia Legislativa do Estado da Califórnia, que visava proibir o uso de armas pelos cidadãos. Mas foi em 1968, após a morte de Luther King e Bobby Hutton, que o número de filiados ao partido cresceu. Também ocorreu uma mudança de comportamento entre os membros. Até então o intuito maior era realizar defesa pessoal contra a violência policial e proteger as comunidades negras, não há como afirmar que tais ideais acabaram, entretanto, o foco passou a ser outro, pois o partido passou a se dedicar aos programas comunitários.

Para Johnson (2002) o declínio dos Panteras Negras se deu pelo fato de o partido ter desmantelado a estrutura nacional, ficando majoritariamente na Califórnia, fazendo com que os recursos ficassem apenas em uma área. Além disso, o autoritarismo de ter o poder em uma única pessoa não agradou aos membros do partido e em 1982 ocorre o fim oficial do Partido dos Panteras Negras.

Dentro desse contexto social, outro nome que se destacou foi o de Martin Luther King, que se tornou o líder do movimento dos direitos civis, defendendo a igualdade racial entre brancos e negros. Essa segregação causou diversas disputas entre negros e brancos, dessa forma, Luther King propunha soluções pacíficas para os conflitos. A partir de 1965, os cidadãos afro-americanos passaram a conquistar alguns direitos perante a lei, por meio do Ato dos Direitos de Voto, sendo garantido "igualdade de oportunidades" e "ação afirmativa" para combater o racismo. (ANDREWS, 1985).

Além de Luther King, outro ator que teve destaque dentro do movimento negro foi Malcolm X. Enquanto Luther King pregava um discurso de não violência, Malcolm X vinha no sentido oposto, o seu discurso mais famoso foi The Ballot or the Bullet, proferido em abril de 1964 , momento em que o governo norte-americano tentou impedir que a população negra tivesse o direito de voto. Assim, Malcolm afirmou que 
se a repressão continuasse, seria necessário pegar em armas. (HALEY, 2015 apud CASTRO, 2009)

Como pode ser visto, a discriminação racial nos Estados Unidos foi e ainda é de longa data. Desde a guerra civil americana (1861 - 1865) que os negros americanos vêm lutando por direitos iguais. Como consequência dessa disputa por direitos, além dos atores citados, e de movimentos como o Black Power e o Partido dos Panteras Negras, houve a criação da All-Negro Comics. A ideia foi do jornalista Orrin C. Evans, sendo essa a primeira revista em quadrinhos criada e desenhada por artistas afro-americanos, no ano de 1947. Evans era membro da NAACP (Associação Nacional pelo Progresso das pessoas de Cor) e acreditava que as histórias em quadrinhos possuíam um potencial educativo, e ao trazer personagens negros, o jornalista acreditava que poderia influenciar positivamente a comunidade negra, especialmente as crianças, devido as questões de representação. Os principais personagens deste quadrinho foram Ace Harlem e o Lion Man. (WESCHENFELDER, 2013).

Com isso, as editoras das revistas em quadrinhos passaram a criar mais personagens negros. Um ano após a aprovação dos direitos civis, a editora Dell Comics lançou o quadrinho Lobo, onde havia um personagem negro criado por Tony Tallaric e D.J. Arneson. (WESCHENFELDER, 2013). 0 personagem era uma junção de herói com cowboy, utilizando armas e roupas de faroeste. Sua habilidade era ser um "super atirador". Porém, as vendas não foram boas, não obtendo sucesso entre o público, o que fez com que o quadrinho fosse cancelado na segunda edição. No mesmo período, Stan Lee e Jack Kirby criaram o personagem do Sargento Fury e o Comando Selvagem. A HQ era baseada em uma temática de guerra e o personagem negro era exaltado por sua coragem nos campos de batalha.

Pode-se perceber, por meio da construção dos personagens negros nas histórias em quadrinhos, a mudança que vinha ocorrendo na sociedade americana. As conquistas dos movimentos negros modificaram parcialmente a sociedade, passando a oportunizar para os cidadãos negros direitos básicos relacionados com educação, moradia e emprego. Cabe ressaltar que tais ações não afirmam o fim do racismo, que ainda nos dias atuais é perceptível na sociedade, seja ela americana ou brasileira. Entretanto, mesmo que a população negra tenha conquistado direitos civis igualitários perante a lei, ainda há muito pelo que lutar. Nos Estados Unidos, um dos mais recentes casos de racismo, ocorrido em maio de 2020, foi o de George Floyd, em Minneapolis. 0 caso gerou diversos protestos e culminou no movimento Black Lives Matter.

No mesmo ano de fundação do Partido dos Panteras Negras, em 1966, surge o primeiro super-herói negro da Marvel, denominado Pantera Negra. Nos primeiros anos de sua criação, o personagem sofreu uma modificação no nome, passando a ser chamado de Leopardo Negro, justamente porque Stan Lee e Jack Kirby não queriam ser associados ao Partido. (HOWE, 2012 apud CASTRO, 2019). Entretanto, essa mudança não permaneceu por muito tempo, e logo o nome voltou a ideia inicial.

Durante os anos de 1960, ocorre uma mudança na figura dos superheróis, que até então eram vistos como inumanos e inalcançáveis. Os 
heróis passaram a ser representados como figuras ansiosas. Havia uma ânsia de lidar com os problemas a sua volta, de saber lidar com a opinião dos outros sobre eles, de como resolver tarefas cotidianas e problemas sociais. No ramo editorial das revistas em quadrinhos, existiam duas principais concorrentes: DC Comics e Marvel Comics. Essa mudança de comportamentos dos heróis acabou se dando especialmente nas revistas da Marvel.

A DC [...] nos idos dos anos 1960, passara a lidar com uma empresa concorrente que apresentava grande expansão: a Marvel Comics. A questão era que em um cenário sob a influência da contracultura e do ativismo político, os personagens da Marvel, principalmente os superheróis, apresentavam muitas novidades que agradavam aos leitores. Stan Lee, o editor da Marvel, dava liberdade de criação a seus roteiristas e desenhistas que explicitamente dialogavam com os temas da época. (CASTRO, 2019, p. 330)

$\mathrm{O}$ autor ainda acrescenta que

Nesse contexto, porém, alguns roteiristas da DC se incomodavam com o viés conservador de sua linha editorial, pois sentiam que enquanto a Marvel ganhava terreno com uma temática de vanguarda, a DC sequer explorava roteiros minimamente voltados às polêmicas de uma época marcada por uma série de movimentos de contestação. (CASTRO, 2019, p. 331).

Dando sequência as histórias de super-heróis negros, a Marvel lançou, em 1969, mais um personagem. O Falcão passou então a ser o primeiro super-herói afro-americano, pois até então havia sido lançado o Pantera Negra, personagem de nacionalidade africana. A primeira aparição do Falcão foi em conjunto com o Capitão América, um super herói criado para representar o patriotismo americano, e responsável por derrotar os maiores inimigos do país nas HQs, como Hitler, nos quadrinhos publicados durante a Segunda Guerra Mundial.

A história de apresentação do Falcão se dá com o inimigo do Capitão o enviando para uma ilha de exilados. No momento em que ocorre uma briga entre o super-herói e os bandidos do local, surge o Falcão para auxiliá-lo. 0 personagem Falcão, conhecido como Samuel Wilson, é representado como um típico jovem que vive no Harlem, localidade em Nova York. O local foi onde Malcolm X foi assassinado. Pode-se perceber que as HQs conversam diretamente com a realidade pela qual o país estava passando. A questão da representatividade foi importante para as editoras. (WESCHENFELDER, 2013). Como pode ser visto, as histórias em quadrinhos tiveram relação direta com os acontecimentos históricos dos Estados Unidos, especialmente no decorrer da ascensão do afrofuturismo, entre os anos de 1950 e 1960.

\section{A projeção de um futuro negro pelo afrofuturismo}

O contexto social e cultura dos Estados Unidos durante os anos de 1980 e 1990 abriu espaço para discussões relacionadas à cibercultura, onde iniciaram-se especulações sobre como seria o futuro, marcado principalmente pela ascensão da internet e computador, discurso da construção de um espaço virtual, onde se questionavam quais seriam as transformações. Já as primeiras discussões sobre afrofuturismo estão ligadas a música negra durantes os anos citados anteriormente. 0

Memorare, Tubarão, v. 8, n. 1, jan./jun. 2021. ISSN: 2358-0593 
momento de maior discussão sobre tais temas foi especialmente ao final dos anos 80, onde houve um "boom" relacionado com a possibilidade de gravações caseiras, com equipamentos eletrônicos de forma automatizada. Ao mesmo tempo, a criação do programa de rádio Afropop Worldwide, com Georges Collinet, buscava apresentar músicas africanas pós-diáspora, e incitava discussões sobre as origens da música eletrônica nos Estados Unidos, onde o House era forte em Chicago e o tecno em Detroit. Esses fatores culminaram na criação de um imaginário para a população negra, aumentando as expectativas sobre o movimento afrofuturista. (FREITAS, 2020).

Especialmente na região de Detroit, a música eletrônica se unia com a realidade social da cidade. Detroit foi a capital industrial estadunidense, abrigando um parque industrial da Ford. Tal fator fez com que o sonho americano fosse ainda mais alimentado, pois a cidade passou por um grande desenvolvimento industrial. Porém, com a grande crise no final do século 20, as fábricas deixaram a cidade e o cenário social mudou completamente. De uma grande potência industrial, sobraram apenas detritos, fábricas semi-utilizadas, isolamento e ruína. (FREITAS, 2020).

Neste cenário de decadência, a juventude negra ficou ainda mais sem perspectivas. Assim, essa mesma juventude, ao observar a cidade, desenvolveu um novo estilo musical, motivados pelos destroços e ideias tecnológicas da cibercultura que estava emergindo. Porém, ao contrário do Hip Hop e Rap, os jovens negros de Detroit não estavam interessados em falar do cenário urbano e da realidade racial de forma direta. A música que eles começam a produzir era abstrata, especulativa. Criava linhas de fuga, narrativas de fuga, para além da realidade. Os artistas passaram a juntar na música o universo da ficção especulativa com esse imaginário de futuros negros. Imaginário onde esses futuros não estavam apresentados. (FREITAS, 2020).

Dando sequência ao contexto apresentado, em 1993, Mark Dery passa a nominar o esse movimento de especulação de um futuro por pessoas negras, assim surge o termo afrofuturismo. Em Black to The Future, Dery realiza uma entrevista com Samuel R. Delany, Greg Tate e Tricia Rose, onde eles discutem sobre as cenas culturais americanas, desde a música (especialmente a música eletrônica negra, o tecno de Detroit), passando pela literatura, artes plásticas, cinema, etc. (FREITAS, 2020).

Anos depois, Mark Dery ressaltou que criou o termo afrofuturismo em parte por frustação, e em parte por revolta de ver apenas pessoas brancas se relacionando com a tecnologia. (DERY, 2020). Cabe ressaltar que não era apenas em propagandas relacionadas a internet que as pessoas negras eram excluídas, em desenhos, como Os Jetsons e em filmes, como Star Wars, que representavam o futuro, há muita pouca presença de pessoas negras.

Outra autora que aborda sobre afrofuturismo é Alondra Nelson (2002), para ela há uma lacuna, um vazio, onde os corpos negros são impossibilitados de habitar. Há um imaginário de sem corpo, sem raça, sem marcação. A negritude torna-se, então um "anti-avatar da vida digital (...) a negritude é construída sempre como oposta às crônicas de um progresso orientado pela tecnologia". (NELSON, 2002, p. 68). Por

Memorare, Tubarão, v. 8, n. 1, jan./jun. 2021. ISSN: 2358-0593 
não haver mais corpos, logo, não existiria a distinção entre raça e gênero, os "eus" se tornam fragmentados no ambiente virtual.

Kodwo Eshun (2003, p. 175) é outro autor que procura pesquisar sobre afrofuturismo. Ele escreve de forma mais ensaística sobre uma ficção sônica através da música. Em suas palavras, o afrofuturismo

Não se limita a corrigir a história do futuro. Nem é uma simples questão de inserir mais autores negros em narrativas de ficção científica. esses métodos são apenas os primeiros passos rumo à realização mais geral que, na formula de Greg Tate, sujeitos afrodiaspóricos vivem o estranhamento que escritores de ficção científica concebem. A existência negra e a ficção científica são uma coisa só.

Ou seja, não é simplesmente pensar o futuro, ou inserir autores negros. 0 que se tem de fato, com o afrofuturismo, é a junção da existência negra com a ficção científica.

O afrofuturismo pode ser compreendido, então, como a junção de uma ficção especulativa junto com as experiências/autorias negras. Essa fabulação reimagina e especula o passado, presente e futuro. (FREITAS, 2020). As temporalidades entram em choque nesse momento. 0 afrofuturismo é um movimento que busca no passado a afirmação no presente e uma especulação de futuro. Assim, em seguida, procura-se pensar justamente sobre essa temporalidade no afrofuturismo.

\section{Regime de tempo no afrofuturismo}

Como citado anteriormente, o afrofuturismo é um movimento que busca nas referências do passado, criar novas possibilidades no futuro para pessoas negras. Há uma certa "viagem no tempo", uma concomitância entre passado e futuro. E para pensar esses tempos, busca-se referências nos conceitos de Cronos e Aion de Gilles Deleuze (2015). Aion é representado como uma linha reta, que foge dos dois sentidos (passado e futuro), isto é, ele é um presente que não se organiza no futuro cronológico. Ao mesmo tempo, ele não possui matéria e é horizontal, ou seja, é um fatiamento do presente. Aion é acontecimento puro. "E o angustiante do acontecimento puro está, justamente, em que ele é alguma coisa que acaba de ocorrer e que vai se passar, ao mesmo tempo, nunca alguma coisa que se passa". (DELEUZE, p. 65-66, 2015). 0 tempo Aion não para de se subdividir, tornando-se ilimitado. Aion não habita o tempo, ele apenas se ramifica. (DELEUZE, 2015). Assim, Aion não tem um passado, presente e futuro organizados.

[...] Aion incorporal, que se desenrolou, tornou-se autônomo desembaraçando-se de sua matéria, fugindo nos dois sentidos ao mesmo tempo do passado e do futuro [...] não tem presente mas recua e avança em dois sentidos ao mesmo tempo, perpétuo objeto de uma dupla questão: o que é que vai se passar? o que é que acabou de passar? (DELEUZE, 2015, p. 65).

Já o Cronos pode ser compreendido como um tempo do agora, ou seja, para ele só existe o tempo do presente; o passado e o futuro são extensões do presente. Em Cronos, o presente se torna corporal, assim, ele não é ilimitado, pois delimita os espaços dos corpos. Diferente de Aion, Cronos é compreendido como circular e infinito. Para Deleuze, Cronos é "circular no sentido de que engloba todo o presente, ele 
recomeça e mede um novo período cósmico após o precedente, idêntico ao precedente" (DELEUZE, 2015, p. 168).

Assim, pode-se entender Cronos como um tempo que está em busca de uma representação, de uma identificação. Porém, essa representação não chega, pois de acordo com o próprio Deleuze, não há como categorizar, cartografar os movimentos e identidades. Assim, por essa incapacidade de se representar, Cronos se duplica e se torna uma representação de si mesmo. Um exemplo de representação é a negritude, pois ela duplica uma sobrevivência ou uma hierarquia de comportamentos que o racismo já organizou, categorizou. Como se fosse um ciclo vicioso, Cronos procura pela representação, não a encontrando, opera a duplicação. Essa duplicação ocorre justamente porque as representações são impossíveis. E por que essas representações são impossíveis? Devido ao fato de que não há como fazer uma cartografia de corpos mortos. Ou seja, esses corpos demandam uma cartografia móvel, o desenho do mapa está em constante mudança, pois os corpos estão sempre em movimento. Assim, pode-se dizer que são corpos e tempos móveis, que tensionam o tempo.

Dentro desse contexto, o afrofuturismo pode ser pensado como tempo aiônico e cronológico? Pode ser compreendido como aiônico pois apresenta essa concomitância entre passado e futuro.

Coincidentemente, o afrofuturismo também entra no tempo cronológico porque Cronos está sempre (re)presentando, ou seja, reapresentando algo. Dentro dessa perspectiva, percebe-se que há um agenciamento de uma expectativa, uma tentativa de restituir uma representação. Mas não é possível, pois há movimento. Esse movimento impossibilita a cartografia, devido a incapacidade de "pegá-lo" ou "capturá-lo". Como o próprio Deleuze afirma, cada fragmento possui singularidades que se repartem, duplicam e geram resultados móveis. Fica claro, então, que ao tentar gerar uma representação de um futuro negro, ocorre uma duplicação. E essa duplicação é resultado de uma organização anterior, já proposta pela sociedade.

Para tornar mais compreensível esses regimes de tempo, pode-se pensar o afrofuturismo. 0 afrofuturismo é esse movimento de retorno ao passado e especulação de futuro, uma busca pela "terra prometida". Em primeiro momento, o afrofuturismo é uma possibilidade cronológica, pois ele busca no passado, na sua história oral, nas músicas, na arte, na dança, na religião, na história da escravidão, nos movimentos dos antepassados o mapeamento das manifestações negras. Porém, Cronos não é suficiente para o afrofuturismo. Assim, esse regime de tempo racha, rompe, e o tempo em Aion surge.

Torna-se importante, então, para essa questão a noção de devirlouco. Pois esta é uma nova tentativa de "dar conta" do tempo no afrofuturismo. Cronos se torna insuficiente, pois é marcado por sua herança racista, pré-determinada pela história contada por homens brancos, que busca categorizar em uma "linha do tempo" os acontecimentos, como se eles fossem imóveis. No instante que ocorre o rompimento de Cronos e o surgimento de Aion não há hora, e são produzidas linhas de fuga que buscam fugir da representação. Para Deleuze, 
O devir-louco da profundidade é, pois, um mau Cronos que se opõe ao presente vivo do bom Cronos. Saturno ruge no fundo de Zeus. O devir puro e desmesurado das qualidades ameaça de dentro a ordem dos corpos qualificados. Os corpos perderam sua medida e não são mais do que simulacros. 0 passado e o futuro como forças desencadeadas se vingam em um só e mesmo abismo que ameaça o presente e tudo o que existe. (DELEUZE, 2015, p. 168-169)

Como foi dito, Cronos "morre" e surge outro regime de tempo, o Aion. 0 tempo em Aion torna-se então um simulacro e se reconstitui como um delírio, porque o simulacro quebra a representação, e assim, passado e futuro se convergem, se fatiam. Assim sendo, pode-se dizer que o afrofuturismo está mais presente no tempo aiônico, que é um tempo emergente, que cria uma estrutura maquínica, ou seja, uma "máquina do tempo", perambulando entre passado e futuro. Por não ter representação, ser apenas um simulacro, não há mais ordem, torna-se algo dionisíaco, "bagunçando" o momento presente, tornando possível olhar para trás e para frente.

Mas, ao mesmo tempo em que o afrofuturismo está dentro do regime aiônico, ele busca uma restituição. Há um esforço de construir uma representação, uma especulação de futuro baseada no passado, nas histórias orais, na fabulação. E essa tentativa de restituição ocorre no presente. Assim sendo, essa tentativa de restituição é a busca por Cronos. Entretanto, Cronos nunca chega, não vem, é sempre um princípio. E por que isso acontece? Devido ao movimento. Fazendo uma alusão ao parágrafo anterior, é como se Cronos fosse a "chave de fenda" da "máquina do tempo". Por isso que, em primeiro momento, o afrofuturismo pode ser compreendido dentro do tempo cronológico, ele "ajusta" o tempo afrofuturista. E isso ocorre porque o ser humano está em constante busca por uma representação, que identifica, que mapeia o tempo negro. É o retorno da cultura de forma fracassada, pois há a necessidade de criar regras e identidades. Mais uma vez revela-se que não há como capturar algo que está em movimento, em constante mudança.

\section{Conclusão}

O afrofuturismo é potência, não é realidade, não se insere numa cronologia da negritude. A tentativa de restituição de uma cultura no afrofuturismo se torna fracassada justamente porque esse movimento bagunça o tempo que os movimentos identitários tentam organizar. Isso não significa que o afrofuturismo deva descartar a identidade. Pelo contrário, a identidade é necessária, mas não deve ser pensada como algo fechado ou imóvel. É uma identidade negada, que deve fazer um movimento antropofágico. Ou seja, devorar a identidade do colono, criando uma nova reafirmação para si. Porém, esses regimes identitários são sempre precários, e permanecem perambulando em uma linha tênue. $O$ afrofuturismo é uma força que, por um lado, é uma identidade demarcadora de desejos. Ao mesmo tempo, ela é frágil, bagunçada. É um movimento político, que não pode se fechar, pois ao fazer isso, ela perde a força. Ao reafirmar uma identidade única, imóvel, ela se fecha e acaba, pois se nega a identidade do outro (esse "outro" é composto por diversas identidades, como por exemplo: gênero, raça, classe, etc.). 
Afrofuturismo é isso, esse tensionamento de tempo, agenciamento entre cultura e cronologia, historicamente historicizado, colocado em cronologia e em uma espécie de relação de infantilidade, uma história de formação, de organização (no sentido de organismo humano mesmo), crescendo e amadurecendo. Cronos se torna precário porque o afrofuturismo o bagunça. Nesse momento, surge o tempo Aion. Porém, esse tempo, ou essa "bagunça" não duram muito tempo, pois o esforço de historicizar o afrofuturismo retorna. Assim sendo, como um vírus, o afrofuturismo bagunça o tempo do organismo, remontando, recriandoo. Porém, ele não o desfaz por completo, pois há sempre um retorno ao regime de tempo cronológico, identitário, imóvel.

Com isso, é possível perceber que, na verdade, não há como permanecer parado ou em um único regime de tempo. Há movimento, há conexões entre o tempo Aion e o tempo Cronos. 0 tempo é diluído, fluido. Por mais que o afrofuturismo perpasse por Aion, ele acaba retornando para Cronos. Pois ocorre uma tentativa no presente de fazer com que as pessoas negras possuam uma representação. 0 afrofuturismo especula o futuro, por meio da ficção, mas essa especulação é para tentar restituir uma "ordem" no agora.

\section{Referências}

ALVES, Amanda Paolo. Do blues ao movimento pelos direitos civis: o surgimento da "black music" nos Estados Unidos. Revista de História, v. 3, n. 1 (2011), p. 50-70. Disponível em: <https://edisciplinas.usp.br/pluginfile.php/4294476/mod_resource/content /1/Alves_Blues_Direitos_Civis.pdf>.

ANDREWS, George Reid. 0 negro no Brasil e nos Estados Unidos. Lua Nova, São Paulo, v. 2, n. 1, p. 52-56, Julho 1985. Disponível em:

<http://www.scielo.br/scielo.php?script=sci_arttext\&pid=S0102-

64451985000200013\&lng=en\&nrm=iso >. Acesso em: 03 maio 2020.

AUGUSTO, Thales. Tribos de Wakanda e suas inspirações na cultura Africana. Portal Gelédes, 2018. Disponível em: <https://www.geledes.org.br/tribos-dewakanda-e-suas-inspiracoes-na-cultura-africana/>. Acesso em 10 abril 2021.

CASTRO, Alexandre de Carvalho. Martin Luther King, Malcolm X, Panteras Negras e Histórias em Quadrinhos: disputas racistas implicadas no primeiro SuperHerói negro da DC Comics. Revista Tempo e Argumento, v. 11, n. 26, pp. 318352, 2019.

COELHO, Frederico Oliveira. Black Power. in: Francisco Carlos Teixeira da Silva (Org.), Enciclopédia de guerras e revoluções do século XX: as grandes transformações do mundo contemporâneo, Rio de Janeiro, Elsevier, 2004.

COELHO, Frederico Oliveira. Black Power. in: Francisco Carlos Teixeira da Silva (Org.), Enciclopédia de guerras e revoluções do século XX: as grandes transformações do mundo contemporâneo, Rio de Janeiro, Elsevier, 2004.

DELEUZE, Gilles. Lógica do Sentido. São Paulo: Perspectivas, 2015.

DERY, Mark (1994). "Black to the future: interviews with Samuel R. Delany, Greg Tate and Tricia Rose" in Flame Wars: the discourse of cyberculture. Durham: Duke University Press. Disponível em: https://www.uvic.ca/victoria- 
colloquium/assets/docs/Black\%20to\%20the\%20Future.pdf. Acesso em: 10 mar. 2020.

ESHUN, Kodwo. More Brilliant Than The Sun: Adventures In Sonic Fiction: Concept Engineered. Quartet Books, 2003.

FREITAS, Kênia. Curso Afrofuturismo, Ficções Especulativas e Fabulações no Cinema Negro. 2020. Online.

HATFIELD, Charles. Hand of Fire: The Comics Art of Jack Kirby. University Press of Mississippi, 2011.

JOHNSON, Ollie A. Explicando a extinção do Partido dos Panteras Negras: o papel dos fatores internos, Caderno CRH, 35, 2002. disponível em: http://www.cadernocrh.ufba.br/ include/getdoc.php?id=957\&article=160\&mode=pdf, acesso em 10 abril 2021.

NAVARRO, Roberto. Quem foram os panteras negras?. Superinteressante, 2019. Disponível em: https://super.abril.com.br/mundo-estranho/quem-foram-ospanteras-negras. Acesso em: 15 mar. 2020.

NELSON, Alondra. Introduction, Future Texts. Social Text, 2002. In: Ponto virgulina, Afrofuturismo, 2020. Disponível em:

<https://www.academia.edu/43805188/Ponto_virgulina_1_Afrofuturismo_Or g_>. Acesso em: 10 abril 2021.

SCIOLI, Tom. Jack Kirby: A Épica Biografia do Rei dos Quadrinhos. Conrad: 2020.

VIANA, Nildo. Heróis e super-heróis no mundo dos quadrinhos. Rio de Janeiro: Achiamé, 2005.

WESCHENFELDER, Gelson Vanderlei. Os Negros nas Histórias em Quadrinhos de SuperHeróis. Revista Identidade!, v. 18, n. 1, p. 67-89, 2013.

Artigo enviado em: 16/04/2021. Aprovado em: 05/07/2021. 